\title{
Psychological Well-Being across Gender and Socio-Economic Status among Middle Adults
}

\author{
Reshma. N. S. ${ }^{1 *}$, Manjula. M. Y. ${ }^{2}$
}

\section{ABSTRACT}

Psychological well-being can be referred to as positive psychological functioning, which involves multidimensional constructs as well as the degree to which an individual perceives himself/herself as functioning well on areas like self acceptance, environmental mastery, personal growth and positive relationships. The current study aims at exploring psychological well-being across gender and socio-economic status among middle adults. The study consists of 266 middle adults (male $=101$, females $=168$ ) selected from 3 different socio-economic status groups (high=75, middle $=114$, low=77). The sample was drawn from urban population from Mangalore city. The age of the sample ranged between 40-55 yrs. Kuppuswamy's socioeconomic status scale (R-2012) and psychological well-being scale by Seema Mehrotra (2013) were administered. The data was analyzed using two-way ANOVA and post hoc test of least significant difference. The results revealed that women have significantly higher positive relations than men. Findings related to different socio-economic groups revealed that, adults belonging to high socio-economic status groups have significantly higher self-acceptance, mastery \& competency, engagement \& growth and overall psychological well-being compared to adults from low socio-economic status group, and significantly higher mastery \& competency, overall psychological well-being than middle socio-economic status group. Middle socioeconomic group adults have significantly higher self-acceptance, engagement \& growth, and overall psychological well-being when compared to adults from low socio-economic status group.

Keywords: Psychological Well-Being, Socio-Economic Status.

Positive psychology defines psychological well-being from Aristotle's perspective of eudemonia. i.e living life according to one's true self. To tap this construct of eudemonic

\footnotetext{
${ }^{1}$ Research Scholar, Department of Post Graduate Studies and Research in Psychology, S.D.M.College (Autonomous), Ujire, Karnataka, India

${ }^{2}$ Professor \& Head, Department of Post Graduate Studies and Research in Psychology, S.D.M.College (Autonomous), Ujire, Karnataka, India

*Responding Author

(C) 2016 I N Reshma, M Manjula; licensee IJIP. This is an Open Access Research distributed under the terms of the Creative Commons Attribution License (http://creativecommons.org/licenses/by/2.0), which permits unrestricted use, distribution, and reproduction in any Medium, provided the original work is properly cited.
} 
happiness, Ryff developed multidimensional model of positive functioning, which includes 6 independent constructs i.e. self acceptance, environmental mastery, personal growth, purpose in life, autonomy and positive relationship with others. According to Ryff psychological well-being is "an active engagement in a number of existential challenges". It is a reflection of one's perception about self in dealing with existential challenges, and degree to which individuals perceive themselves as functioning well on these 6 major areas of life (Ryff 1989). The variation on this such as, diminished positive psychological well-being indicates, difficulties in coping with major transitions in life (Abbot, et.al 2008, Kwan, Love \& Ryff 2003), while enhanced psychological well-being indicates successful formation of identity (Vleioras \& Bosma 2005).

\section{Gender and psychological well-being}

The existing research in the area of psychological well-being has shown, gender differences for positive relationship with others and for personal growth, with women having higher scores than men for both the dimensions ( Ryff 1989, Ryff \& Keyes 1995). In another study it was found that, women not only score significantly higher than men on positive relations with others, but also on purpose in life and personal growth, while men scored significantly higher than women on environmental mastery (Lindfors, et.al 2006).

\section{Socio-economic status and psychological well-being}

Socio-economic status (SES) is an influential factor on individual well-being. As Pearlin (1989) rightly noted that the, social structure and arrangements of people's lives and their repeated experiences from these social factors have deep impact on one's well-being. Ryff and Singer (2008) also argued that well-being and human fulfillment are deeply influenced by the surrounding context of people's lives. Social factors such as, education, occupation, income, are the significant factors which have their impact on psychological well-being. Literature related to education and psychological well-being reveals that educational standards are strongly positively linked with psychological well-being, and association is especially pronounced for personal growth and purpose in life. In another study, it was found that, individuals with higher education levels experience higher overall psychological well-being than lower level education groups (Ryff \& Singer 2008, Marmot, et.al 1998, Marmot, Ryff, Bumpass Shipley, and Marks 1997, Ryff, et.al 1999, Keyes, et.al 2002, Ryff 1989). Research related to income and psychological well-being, reveals that the higher income levels predicts higher psychological well-being scores, and are strongly related to Purpose in Life (Clarke, et.al 2000).

In general, socio-economic factors can be a good indicator in determining one's psychological well-being (e.g. Ryff \& Singer 2008). Current study focuses on exploring how different socioeconomic status groups vary on psychological well-being.

\section{METHODOLOGY}

Present research is exploratory in nature. It adopts 2 X 3 factorial design and purposive sampling technique. The study consists of 266 middle adults (male=101, females=168) selected from 3 
different socio-economic status (high=75, middle=114, low=77). The sample was drawn from Mangalore city. The age of the sample ranged between 40-55 yrs.

\section{Inclusion criteria}

Middle adults married living with spouse; having children and working.

\section{Tools}

Kuppuswamy's socio-economic status scale-R (Kumar, et.al 2012): The questionnaire covered three areas viz. education, occupation, and monthly income. It has good internal reliability and validity.

Psychological well-being scale (Mehrotra, S 2013): Psychological well-being is self report questionnaire. The questionnaire consists of 4 domains. The reliability alpha for self-acceptance is 0.72 , mastery \& competence is 0.72 , positive relation is 0.69 ,

\section{Procedure} engagement \& growth is 0.74 and for overall psychological well-being it is 0.83 .

Heads of different organizations were met, purpose of the research was explained and their consent was obtained to collect data from a few of the employees of their organization. Subsequently the employees who met the inclusion criteria were approached and the purpose of the study was explained to them and written informed consent was obtained from the willing participants. They were first asked to fill Kuppuswamy's socio-economic status scale, followed by that, they were asked to fill the psychological well-being questionnaire. The total time for filling both the scales was 10 to 15 minutes.

\section{Statistical Analysis}

The data was coded for computer analysis. Two-way ANOVA and Post hoc test of Least Significant Difference (LSD) was carried out. For levels of significance, 0.05 and 0.01 levels were considered.

\section{RESULTS AND DISCUSSION}

Table 1, F ratio for gender and socio-economic status on domains of psychological well-being.

\begin{tabular}{|c|c|c|c|c|c|}
\hline Variables & Domains & $\begin{array}{l}\text { Sum of mean } \\
\text { square }\end{array}$ & df & $\mathbf{F}$ & Significance \\
\hline $\begin{array}{l}\text { Gender } \\
\text { SES } \\
\text { Gender*SES }\end{array}$ & Self-acceptance & $\begin{array}{l}8.501 \\
112.12 \\
17.19\end{array}$ & $\begin{array}{l}1 \\
2 \\
2\end{array}$ & $\begin{array}{l}.803 \\
5.29 \\
.812\end{array}$ & $\begin{array}{l}.371 \\
.006 \\
.445\end{array}$ \\
\hline $\begin{array}{l}\text { Gender } \\
\text { SES } \\
\text { Gender*SES }\end{array}$ & Mastery \& competency & $\begin{array}{l}21.052 \\
601.680 \\
70.83\end{array}$ & $\begin{array}{l}1 \\
2 \\
2\end{array}$ & $\begin{array}{l}.511 \\
7.30 \\
.860 \\
\end{array}$ & $\begin{array}{l}.475 \\
.001 \\
.424 \\
\end{array}$ \\
\hline $\begin{array}{l}\text { Gender } \\
\text { SES } \\
\text { Gender*SES }\end{array}$ & Positive relations & $\begin{array}{l}208.65 \\
149.18 \\
6.97\end{array}$ & $\begin{array}{l}1 \\
2 \\
2\end{array}$ & $\begin{array}{l}8.08 \\
2.89 \\
.135 \\
\end{array}$ & $\begin{array}{l}.005 \\
.057 \\
.874 \\
\end{array}$ \\
\hline $\begin{array}{l}\text { Gender } \\
\text { SES } \\
\text { Gender*SES }\end{array}$ & Engagement \& growth & $\begin{array}{l}.197 \\
215.44 \\
80.15 \\
\end{array}$ & $\begin{array}{l}1 \\
2 \\
2\end{array}$ & $\begin{array}{l}.013 \\
6.949 \\
2.586 \\
\end{array}$ & $\begin{array}{l}.910 \\
.001 \\
.077 \\
\end{array}$ \\
\hline $\begin{array}{l}\text { Gender } \\
\text { SES } \\
\text { Gender*SES }\end{array}$ & $\begin{array}{c}\text { Overall Psychological } \\
\text { well-being }\end{array}$ & $\begin{array}{l}462.48 \\
3720.2 \\
218.0 \\
\end{array}$ & $\begin{array}{l}1 \\
2 \\
2\end{array}$ & $\begin{array}{l}2.73 \\
10.98 \\
.644 \\
\end{array}$ & $\begin{array}{l}.100 \\
.001 \\
.526 \\
\end{array}$ \\
\hline
\end{tabular}


Psychological Well-Being across Gender and Socio-Economic Status among Middle Adults

Table 2, Post hoc test of Least Significant Differences, across socio-economic status on domains of psychological well-being

\begin{tabular}{|l|ll|l|l|}
\hline \multirow{2}{*}{ Domains } & \multicolumn{2}{|l|}{ Socio-economic status } & Mean difference & Significance \\
\hline Self-acceptance & groups & & \\
& High & Middle & .59 & .223 \\
& High & Low & 1.70 & .001 \\
& Middle & Low & 1.10 & .022 \\
\hline \multirow{3}{*}{ Mastery \& competency } & High & Middle & 2.52 & .009 \\
& High & Low & 4.23 & .001 \\
& Middle & Low & 1.71 & .073 \\
\hline Positive relations & High & Middle & 1.51 & .128 \\
& High & Low & 1.96 & .018 \\
& Middle & Low & .80 & .284 \\
\hline Orowth \& engagement & High & Middle & .87 & .139 \\
& High & Low & 2.46 & .001 \\
well-being & Middle & Low & 1.59 & .006 \\
\hline
\end{tabular}

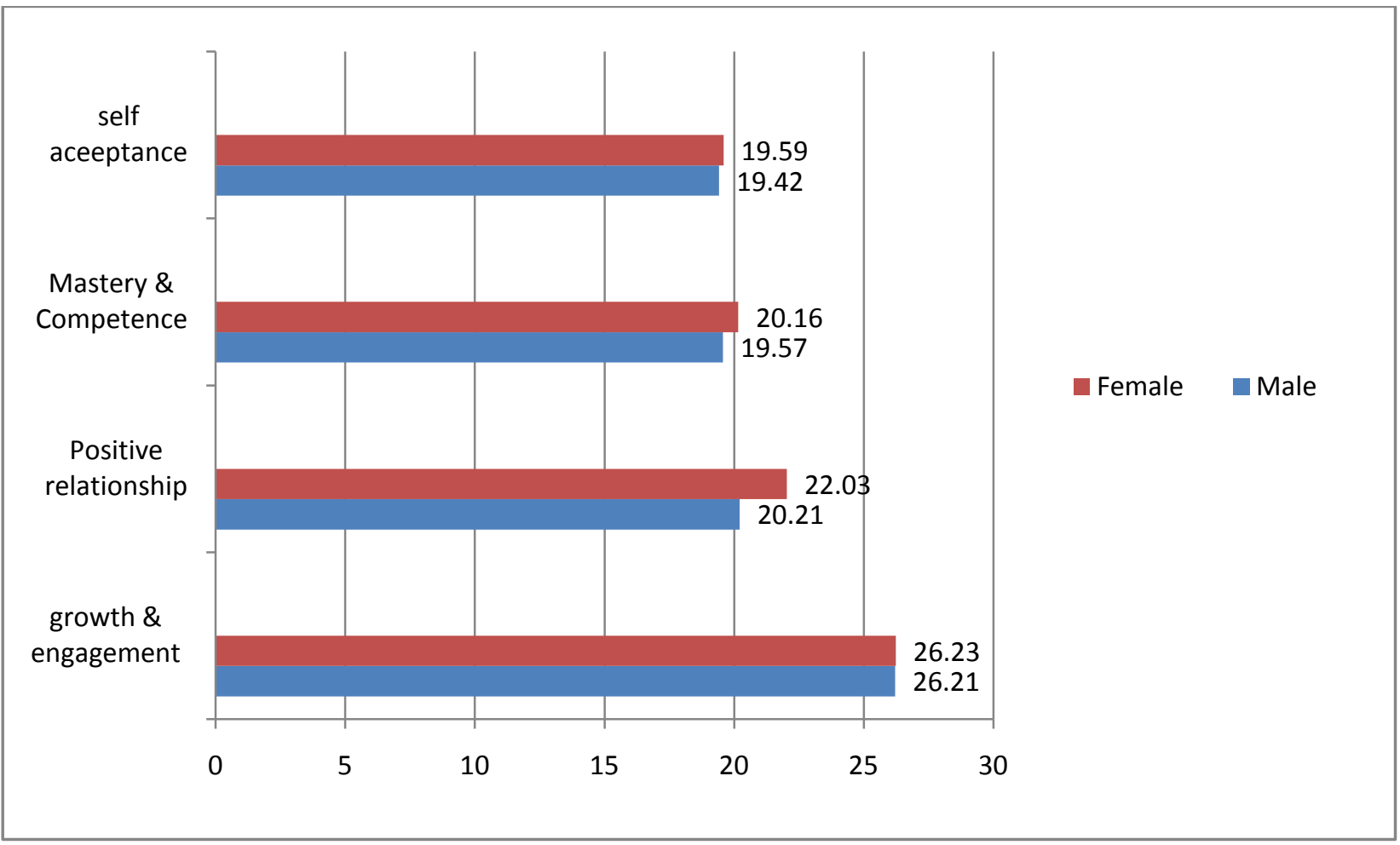

Figure 1.1 , Mean score of Male and female participants on domains of psychological wellbeing. 


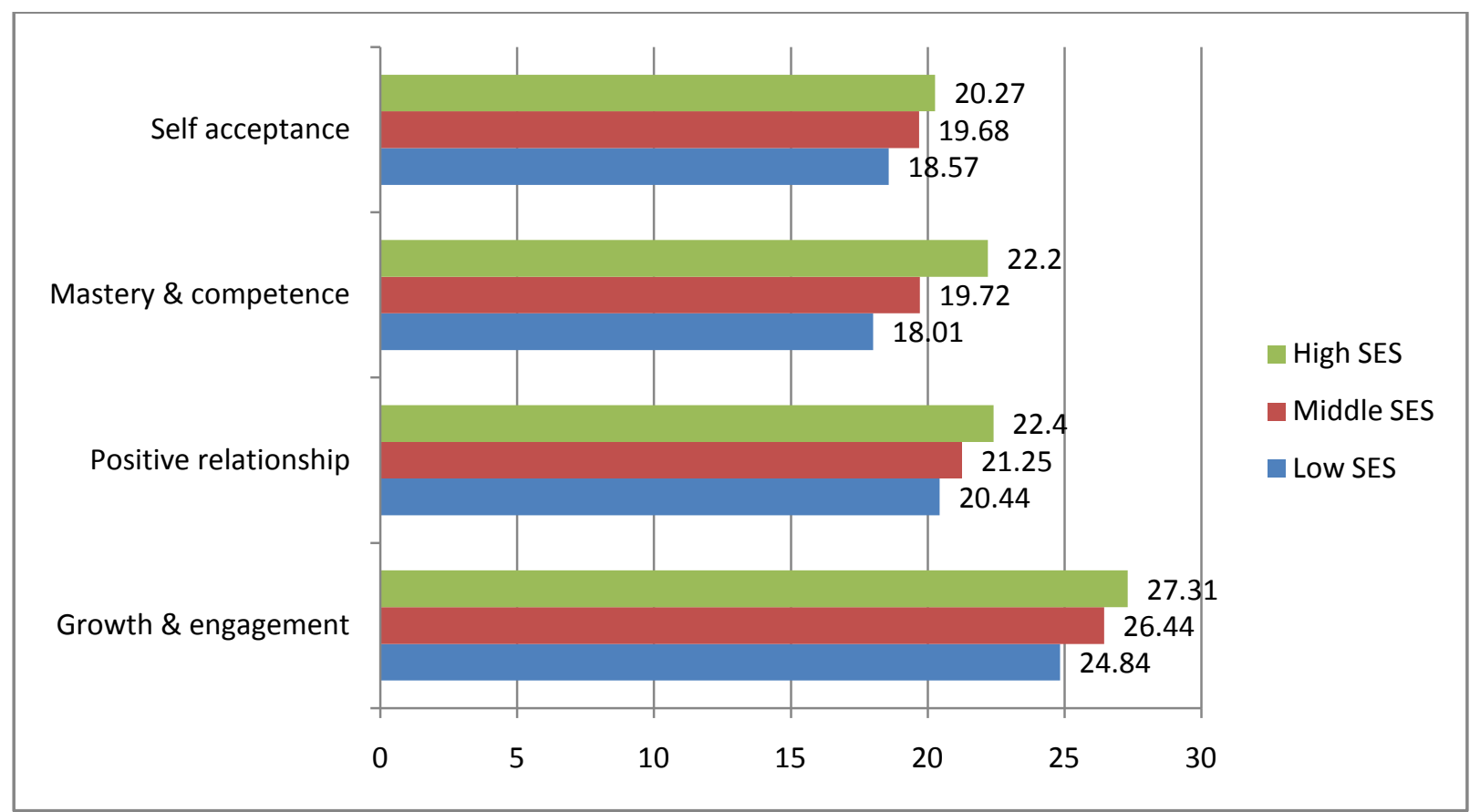

Figure1.2, Mean score of different socio-economic status groups on dimensions of psychological well-being.

\section{GENDER AND PSYCHOLOGICAL WELL-BEING:}

The result reveals significant gender differences on positive relations, wherein women have significantly higher positive relations than men. Existing literatures also (Ryff 1989, Ryff \& Keyes 1995, Lindfors, Berntsson, Lundberg 2006) supports similar gender differences on domain of positive relationship. In all the other areas of well-being as well as overall psychological wellbeing no gender differences are noticed.

\section{SOCIO-ECONOMIC STATUS AND PSYCHOLOGICAL WELL-BEING:}

Significant differences are noticed between middle adults from different socio-economic status groups on psychological well-being and on the different domains of psychological well-being namely self-acceptance, mastery \& competence, growth \& engagement and overall psychological well-being.

The adults belonging to high socio-economic status groups have significantly higher levels of self-acceptance, mastery \& competence, growth \& engagement and overall psychological wellbeing when compared to adults belonging to lower socio-economic status groups and have significantly higher mastery \& competency and overall psychological well-being than adults belonging to middle socio-economic status groups. Similarly, adults belonging to middle socioeconomic status groups also are found to have significantly higher self-acceptance, engagement \& growth and overall psychological well-being when compared to adults belonging to lower socio-economic status groups. 
Studies indicates that, the adults belonging to higher socio-economic level have higher levels of optimism, self-esteem and need for achievement, and have greater aspirations, high competitiveness in terms of their education and mastery (Aston and McLanahan, 1991; Cassidy and Lynn, 1991). They also hold high demanding job profile and enjoy high social status in the society. The studies also have found that they adopt direct coping pattern, such as problem focussed coping and cognitive reappraisal techniques in tackling stressful situation (Lever, 2005). It is found that the problem focussed coping pattern, improve environmental mastery, and purpose in life. While use of reappraisal facilitates environmental mastery, personal growth, self acceptance, autonomy, clearer purpose in life, autonomy, and better relationship with others (Balzarotti,et.al 2014).

Lever 2005 found that the low socio-economic group adults cope with stress in the least direct way (using strategies such as avoidance, escapism, minimization, etcetera), and have an external locus of control and lack orientation toward competitiveness and mastery and reports less subjective well-being than middle and high socio-economic group adults (Lever, 2005). Study done by Greenlee and Lantz (1993) found that the stress caused by limited economic resources generates feelings of depression, anxiety and worry, as well as use of emotional strategies for coping. Use of Emotional coping more strongly associated with declining well-being with respect to environmental mastery, self acceptance and chronic use of suppression linked to negative emotion, and have worse coping, lower self esteem, less optimistic attitude about the future, lack of social relationships and support( Gross \& John 2003).

\section{CONCLUSION}

The findings reveal that women have significantly higher positive relations than men. The psychological well-being among adults from different socio-economic status groups reveals that the adults belonging to lower socio-economic status groups have significantly lower psychological well-being on all the dimensions than middle and upper socio-economic status group adults.

\section{REFERENCES}

Abbey, A. and F. Andrews: 1985, 'Modeling the psychological determinants of life quality', Social Indicators Research 16, pp. 1-34.

Abbott. Rosemary. A., Croudace.Tim. J., Ploubidis George. B., Kuh. Diana. (2008). The relationship between early personality and midlife psychological well-being: evidence from a UK birth cohort study. Social Psychiatry Epidemiology 43:679-687

Aston, N. M. and S. S. McLanahan: 1991, 'Family structure, parental practices and high school completion', American Sociological Review 56, pp. 309-320.

Balzarotti, S., Biassoni, F.,Villani, D., Pranas, A., Velothi, P. (2014). Individual differences in cognitive emotional regulation: implication for subjective and psychological well being. Journal of happiness studies. 10.

Cassidy, T. and R. Lynn: 1991, 'Achievement motivation, educational attainment, cycles of disadvantage and social competence: some longitudinal data', British Journal of Educational Psychology 61, pp. 1-12. 


\section{Psychological Well-Being across Gender and Socio-Economic Status among Middle Adults}

Clarke, P. J., Marshall, V. W., Ryff, C. D., \& Rosenthal, C. J. (2000). Well-being in Canadian seniors: Findings from the Canadian study of health and aging. Canadian Journal on Aging, 19, 139-159

Greenlee, R. and J. Lantz: 1993, 'Family coping strategies and the rural Appalachian working poor', Contemporary Family Therapy: An International Journal 15(2), pp. 121-137.

Keyes, C. L. M. (2002). Mental health continuum: From languishing to flourishing in life. Journal of Health and Social Research, 43, 207-222.

Kumar,B.P.Ravi., Dudala, Shankar. Reddy., Rao, A.R. (2013). Kuppuswamy’s socio-economic status scale, a revision of economic parameters for 2012. International Journal of Research and Development of Health.

Kwan, C. M. L., Love, G. D., \& Ryff, C. D. (2003). The role of self-enhancing evaluations in a successful life transition. Psychology and Aging, 18, 3-12.

Lever, Joaquina. Palmar., Pinol, Nuria. Lauza, gorta., Uralde, Jorge. Hernandez. (2005). Personality, psychological resources and subjective well-being. Social indicators research, vol 73, no3 pp. 375-408.

Lindfors, P., Berntsson, L., \& Lundberg, U. (2006).Factor structure of Ryff'spsychological wellbeing scales in Swedish female and male white-collar workers. Personality and Individual Differences, 40, 1213-1222.

Marmot, M. G., Fuhrer, R., Ettner, S. L., Marks, N. F., Bumpass, L. L., \& Ryff, C. D (1998). Contribution of psychosocial factors to socioeconomic differences in health. Milbank Quarterly, 76, 403 - 448.

Marmot, M., Ryff, C. D., Bumpass, L. L., Shipley, M., \& Marks, N. F. (1997).Social inequalities in health: next questions and converging evidence. Social Science and Medicine, 44, 901 $-910$.

Mehrotra, S., Tripathi, R. and Banu, H. (2013) Psychological well being: Reflections on an elusive construct and its assessment, The Journal of Indian Academy of Applied Psychology. Vol.39, No.2, 189-195

Pearlin, L. I. (1989). The sociological study of stress. Journal of Health and Social Behaviour, 30(3), 241-259.

Ryff, C. D. (1989). Happiness is everything, or is it? Explorations on the meaning of psychological well-being. Journal of Personality and Social Psychology, 57,1069-1081.

Ryff, C. D., \& Keyes, C. L. M. (1995). The structure of psychological well-being revisited. Journal of Personality and Social Psychology, 69, 719-727.

Ryff, C. D., \& Singer, B. (2008). Know thyself and become what you are: A eudemonic approach to psychological well-being. Journal of Happiness Studies, 9(1), 13-39.

Ryff, C. D., Magee, W. J., Kling, K. C., \& Wing, E. H. (1999). Forging macro-micro linkages in the study of psychological well-being. The self and society in aging processes (pp.247278). NewYork, NY: Springer.

Vleioras, G., \& Bosma, H. A. (2005). Are identity styles important for psychological well-being? Journal of Adolescence, 28, 397 - 409. 